\title{
Investigation of the Effect of Concentration on Molecular Aggregation of Cyanine Dyes in Aqueous Solution
}

\author{
John Kunzler, Leen Samha, Renwu Zhang, and Hussein Samha* \\ Department of Physical Science \\ Southern Utah University \\ Cedar City, Utah 84720 USA
}

Received: October 8, 2010 Accepted: March 1, 2011

\begin{abstract}
The aggregation of the cyanine dye, 3,3'-disulfobutyl-5,5'-dichloro thiacarbocyanine triethylamine, (NK-3796) in aqueous solution was investigated using absorption and emission spectroscopy. The equilibrium, $\mathrm{n}$ (monomer) $\leftrightarrows-\mathrm{n}$ (dimer) $\leftrightarrows(\mathrm{H} \text {-aggregate })_{\mathrm{n}}$, was observed over a series of dye concentrations ranging from $10^{-4} \mathrm{mM}$ to $0.1 \mathrm{mM}$. At concentrations $<10^{-3} \mathrm{mM}$, the dye exists in solution mostly in the monomeric form. However, dimers become more significant when the concentration of the dye exceeds $10^{-2} \mathrm{mM}$. Unlike the substituted dye in the 9th position, the NK3796 dye tends to form $\mathrm{H}$-aggregates at higher concentration $\left(>10^{-1} \mathrm{mM}\right)$. Monomers and dimers exhibit strong emission in the visible region. Also notable, is that the emission from the $\mathrm{H}$ aggregates was very weak due to self quenching.
\end{abstract}

\section{INTRODUCTION}

Aggregates generated by self assembly have captured the attention of scientists for their unique and unusual spectroscopic properties [1-5]. Cyanine dyes, in particular, are known for their distinctive ability to form several types of aggregates, mainly $\mathrm{H}$-aggregates and $\mathrm{J}$ Aggregates (Scheme 1), on solid supporting surfaces and in solutions [6-9]. Aggregate formation is accompanied by dramatic changes in both absorbance and fluorescence of the dyes. In the case of $\mathrm{H}$ aggregates, a broad blue shift absorbance is observed, while the J-aggregates are distinguished by a narrow, red shift absorbance band, relative to the monomeric dye, in the visible region.

\footnotetext{
* Corresponding author
}

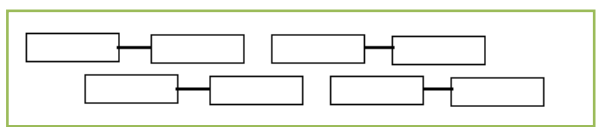

(a) J-aggregate

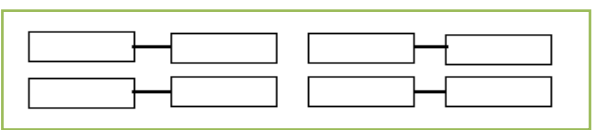

(b) $\mathrm{H}$-aggregate

Scheme 1. Schematic illustrations of the aggregates.

J-aggregates are useful in photography, optical device technology, and as spectral sensitizers. Recently, several reports describing the formation of $\mathrm{J}$ aggregates of cyanine dyes for different applications have been published [9-12]. This work reports the effect of concentration of the cyanine dye, 3,3'-disulfobutyl-5,5'dichloro thiacarbocyanine triethylamine, 
(NK-3796) illustrated in Figure 1, on the molecular aggregation in aqueous solutions and compares the results with a similar dye that could behave in a parallel way.<smiles>CN1/C(=C/C=C/c2sc3ccc(Cl)cc3[n+]2C)Sc2ccc(Cl)cc21</smiles>

NK-3796

Figure 1. Molecular Structure of NK-3796

\section{EXPERIMENTAL SECTION}

The following aqueous solutions, $9.05 \times 10^{-7} \mathrm{M}, 9.05 \times 10^{-6} \mathrm{M}, 9.05 \times 10^{-5} \mathrm{M}$, and $9.05 \times 10^{-4} \mathrm{M}$, of the dye were freshly prepared by diluting a stock solution (9.05 $\left.\mathrm{x} 10^{-4} \mathrm{M}\right)$ at room temperature before being used. High purity de-ionized water of measured $\mathrm{pH}=7$ was used to prepare all the solutions. No buffer solutions were used in any of the experiments. The absorbance of the dye in the solutions was recorded using an HP Agilent UV-Vis spectrophotometer. Then the emission was recorded using Photon Technology Inc. (PTI) fluorometer.

\section{RESULTS AND DISCUSSION}

Figure 2 illustrates the absorbance of the cyanine dye, NK-3796, in solution at different concentrations ranging from $9.05 \mathrm{x}$ $10^{-4} \mathrm{M}$ to $9.05 \times 10^{-7} \mathrm{M}$. Clearly, the molecular distribution of the dye in solution is dependent on its concentration. At concentration $<10^{-6} \mathrm{M}$, the dye existed in solution mainly in the monomeric form. Dimer became more significant when the concentration of the dye exceeds $10^{-5} \mathrm{M}$. This claim is supported by the increase in the intensity of the shoulder peak at $520 \mathrm{~nm}$ as the concentration increases to $9.05 \times 10^{-6}$ $M$ (Figure 2). Unlike the substituted dye in the 9th position (meso-methyl and mesoethyl thiacarbocyanine) [4,5], the NK-3796 dye tends to form $\mathrm{H}$-aggregate at higher concentration $\left(>10^{-4} \mathrm{M}\right)$ as indicated by the broad blue shift absorbance in Figure 2. As the concentration of the dye reaches $9.05 \mathrm{x}$ $10^{-5} \mathrm{M}$, the dimeric peak $(520 \mathrm{~nm})$ starts to get broader. At $9.05 \times 10^{-4} \mathrm{M}$, the broadness of the peak transforms into a well developed blue shifted peak which is typical of $\mathrm{H}$-aggregate. Of the dyes we tested, the absence of any red shifted narrow bands suggests no J-aggregates were formed in any of the solutions tested including the solution of higher concentration. Due to limited solubility of the dye, we were only able to prepare concentrations as high as $0.1 \mathrm{mM}$

Clearly, the effect of mesosubstituent (substituent in the 9 position on the dye) has a direct effect on the self assembling of the dye [14,15]. While a meso-ethyl thiacarbocyanine dye is known to self-assemble into J-aggregate, the equivalent meso-methyl dye produces either $\mathrm{J}$ or $\mathrm{H}$ aggregate as a function of dye concentration [5]. The unsubstituted dye, NK-3796, however, is not capable of self assemble into $\mathrm{J}$-aggregate even at high concentration. We attribute this to the steric effect that is caused by the alky group on the 9th position of the dye. The consistency in the aggregation behavior of the three dyes (unsubstituted, meso-methyl, and meso-ethyl thiacarbocyanine) where $\mathrm{H}, \mathrm{H}$ and $\mathrm{J}$, and only $\mathrm{J}$ aggregate are possible respectively fits the steric effect argument perfectly.

The emission of the dye was also recorded using different concentrations (Figure 3). In each case the emission is typical of that of monomers and dimers. The emission recorded for $9.05 \times 10^{-7} \mathrm{M}$ (blue) and $9.05 \times 10^{-6} \mathrm{M}$ (red) solutions suggest that monomers are the dominant species in solution at concentrations less than $10^{-5} \mathrm{M}$. However, the emission recorded for $9.05 \times 10^{-5} \mathrm{M}$ (green) solution is very interesting. Its broad red-shifted emission 


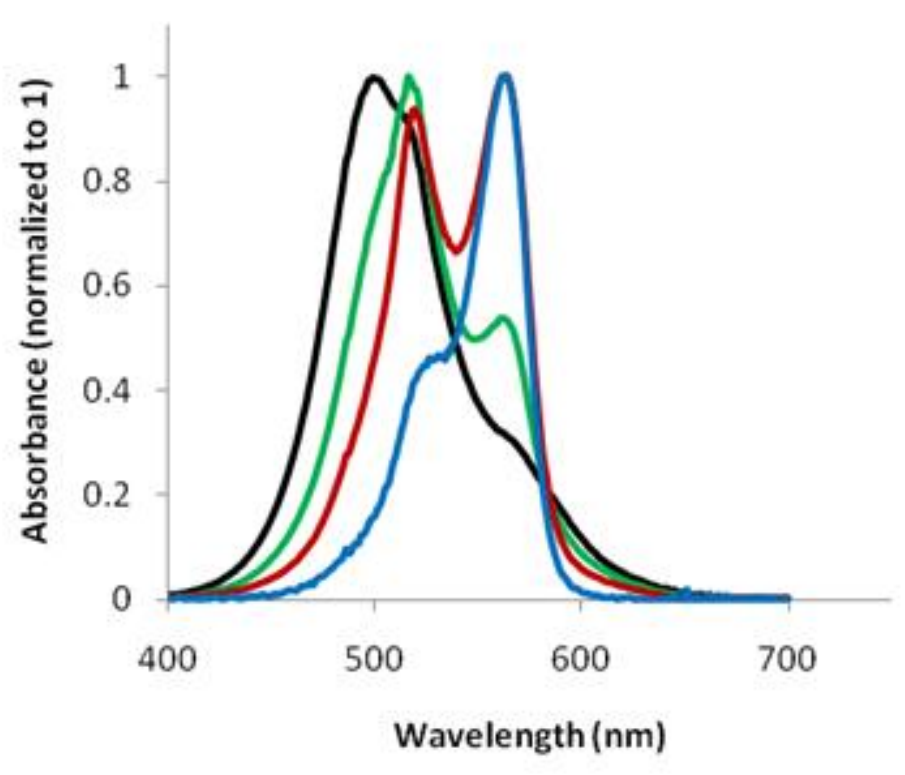

Figure 2. Normalized absorbance of NK-3796, $9.05 \times 10^{-7} \mathrm{M}$ (blue), $9.05 \times 10^{-6} \mathrm{M}$ (red), $9.05 \times 10^{-5} \mathrm{M}$ (green), $9.05 \times 10^{-4} \mathrm{M}$ (black). Note that the absorbance was recorded using quartz cells with an optical path length of $0.1 \mathrm{~mm}$ for $9.05 \times 10^{-4} \mathrm{M}, 0.2 \mathrm{~mm}$ for $9.05 \times 10^{-5} \mathrm{M}$, and $10 \mathrm{~mm}$ for the rest of solutions.

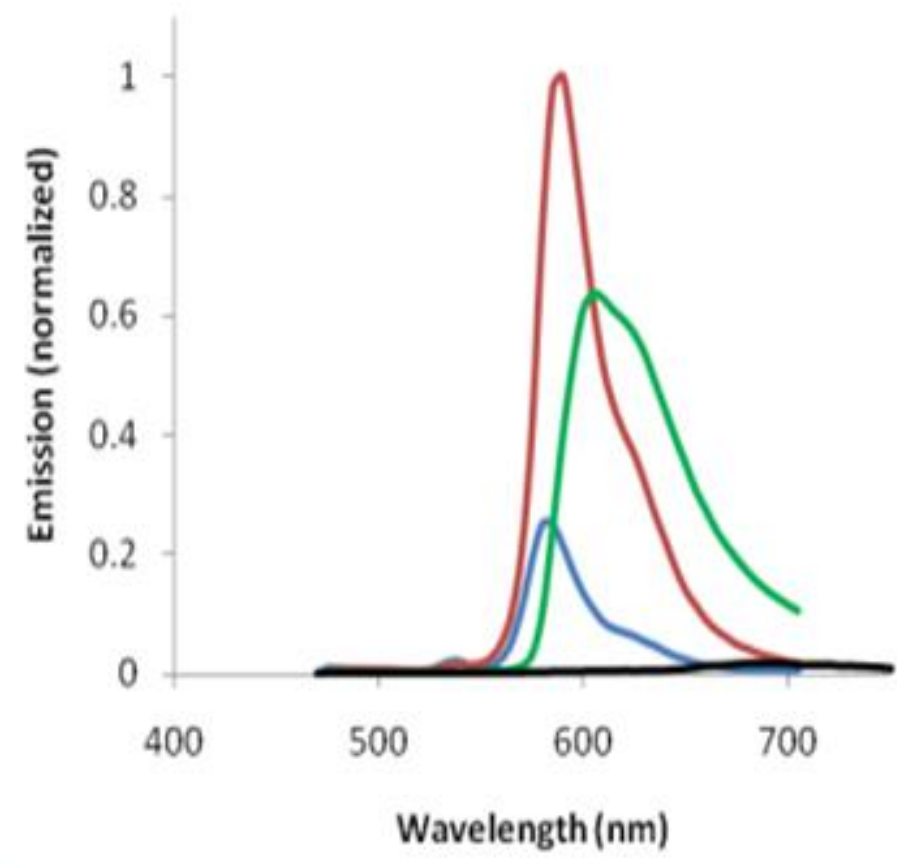

Figure 3. Normalized emission of NK-3796, $9.05 \times 10^{-7} \mathrm{M}$ (blue), $9.05 \times 10^{-6} \mathrm{M}$ (red), $9.05 \times 10^{-5} \mathrm{M}$ (green), $9.05 \times 10^{-4} \mathrm{M}$ (black), $\lambda_{\text {ex }}=450 \mathrm{~nm}$ 
suggests the formation of dimer $\leftrightarrows \mathrm{H}$ aggregate equilibrium. The variation in the intensity of the emission peaks recorded for $9.05 \times 10^{-7} \mathrm{M}$ (blue) and $9.05 \times 10^{-6} \mathrm{M}$ (red) solutions is due to a concentration effect. However, the lower intensity of the peak recorded for $9.05 \times 10^{-5} \mathrm{M}$ (green) solution is attributed to some self quenching of the $\mathrm{H}$ aggregate as it is also the case when $9.05 \times 10^{-4} \mathrm{M}$ (black) solution is used.

\section{CONCLUSION}

NK-3796 forms different types of aggregates in solution which depend on the dye concentration. In dilute solution, the dye exists in the monomeric form. As the concentration increases, the dye tends to form dimers then $\mathrm{H}$-aggregate. Unlike the substituted dye in the 9th position, NK-3796 seems to favor the formation of $\mathrm{H}$-aggregate and not the J-aggregate at higher concentration. The fluorescence of the $\mathrm{H}$ aggregate is very weak compared to that of the monomers and this is due to self quenching.

\section{REFERENCES}

1. Chowdhury, A.; Wachsmann-Hogiu, S.; Bangal, P. R.; Raheem, I.; Peteanu, L. A. J. Phys. Chem. B., 2001, 105, 12196.

2. Gilman, P. B. J. Photoger. Sci. Eng., 1974, 18, 418.

3. Wang, Y. Chem. Phys. Lett., 1986, 126, 209.

4. Kometani, N.; Nakajima, H.; Asami, K.; Yonezawa, Y.; Kajimoto, O. J. Phys. Chem. B, 2000, 104, 9630-9637.

5. Yao, H.; Isohashi, T.; Kimura, K. J. Phys. Chem. B, 2007, 111 (25), 71767183.

6. Hada, H.; Hanawa, R.; Haraguchi, A.; Yonezawa, Y. J. Phys. Chem., 1985, 89, 560.

7. Misawa, K.; Ono, H.; Minoshima, K.; Kobayashi, T. Appl. Phys. Lett., 1993, 63, 577.
8. Sluch, M. I.; Vitukhonovsky, A. G.; Yonezawa, Y.; Sato, T.; KKunisawa, T. Opt. Mater, 1996, 6, 261.

9. Baumann, D.; Clark, B; Garlick, J.; Samha, H. American Journal of Undergraduate Research, 2009, 7(4), 16.

10. Kato, N.; Mikami, Y.; Serata, T.; Uesu, Y., Trans. Mater. Res. Soc. Jpn., 2002, 27, 341.

11. Kato, N.; Prime, J.; Katagiri, K.; Caruso, F., Langmuir, 2004, 20, 5718.

12. Yamamoto, K.; Kato, N.; Uesu, Y., Trans. Mater. Res. Soc. Jpn., 2006, 3, 569.

13. Brinker, C.J.; Scherer, G.W., Sol-Gel Science, Academic Press, New York, 1989.

14. Varnavsky, O. P.; Van der Auweraer, M.; Vitukhnovsky, A. G.; Scheblykin, I. G., Opt. Spectrosc. 1998, 84, 834.

15. Scheblykin, I. G.; Bataiev, M. M.; Van der Auweraer, M.; Vitukhnovsky, A. G., Chem. Phys. Lett. 2000, 316, 37.

\begin{tabular}{l} 
SUU Southern Utah University \\
Through more than 110 years of history, \\
Southern Utah University has evolved from a \\
teacher training institution to its current role as \\
a comprehensive, regional university offering \\
graduate, baccalaureate, associate and \\
technical programs. From the time of its \\
founding, SUU has placed students first by \\
featuring personalized and participative \\
classes, combined with competent, qualified \\
and supportive faculty. National parks and \\
recreation surround Cedar City. Skiing is 40 \\
minutes away at Brian Head. For a wider range \\
of metropolitan service, the city of Las Vegas is \\
two-and-a-half hours south, Provo two-and-a- \\
half hours north. $\quad$ www.suu.edu \\
\hline
\end{tabular}

